\title{
Utilização da técnica AHP nos índices de vulnerabilidade natural a erosão na bacia hidrográfica do Igarapé São Francisco como suporte para o ordenamento territorial
}

O avanço da sociedade com a utilização de novas tecnologias somada a necessidade de seu desenvolvimento, requerem cada vez mais o uso extensivo dos recursos naturais, provocando o desequilíbrio dinâmico na natureza. A bacia hidrográfica do Igarapé São Francisco, situada nos municípios de Campo Novo e Buritis, está em uma área de forte crescimento de fronteira agrícola, com isso apresenta intensos processos erosivos, consequência da indevida utilização dos solos. Desta forma, há a necessidade de dispor um planejamento ambiental de modo a instituir indicações e ações para uma apropriada gestão de um ambiente natural. Este trabalho utilizou o Plano Agropecuário e Florestal de Rondônia (RONDÔNIA, 2001) como base para a análise das informações fitográficas na produção da carta de Vulnerabilidade Natural a Erosão, utilizando a metodologia proposta por Crepani et al. (1996; 2001). Tal método instrui e auxilia na consecução de estratégias e ações regionais, sendo, neste estudo, associada a técnica de assistência com multicritério para tomada de decisões, conhecida como técnica de Análise Hierárquica Processual (AHP) desenvolvida por Saaty (1977), que complementa a eficácia do método. A pesquisa, por fim, apura a suscetibilidade natural dos ambientes aos processos erosivo, tendo como produto a carta de vulnerabilidade natural a erosão, categorizando a área segundo grau de vulnerabilidade ambiental aos processos erosivos.

Palavras-chave: Planejamento ambiental; Vulnerabilidade Natural a Erosão; AHP.

\section{Use of the AHP technique in the natural vulnerability indexes to erosion in the São Francisco Igarapé hydrographic basin as a support for territorial ordering}

\begin{abstract}
The advancement of society with the use of new technologies added to the need for its development increasingly requires the extensive use of natural resources, causing the dynamic imbalance in nature. The hydrographic basin of Igarapé São Francisco, located in the municipalities of Campo Novo and Buritis, is in an area of strong growth in the agricultural frontier, with which it presents intense erosion processes, consequence of the improper use of the soil. Thus, there is a need to have environmental planning in order to institute indications and actions for an appropriate management of a natural environment. This work used the Agricultural and Forestry Plan of Rondônia (RONDÔNIA, 2001) as a basis for the analysis of phytographic information in the production of the Natural Vulnerability to Erosion chart, using the methodology proposed by Crepani et al. (1996; 2001). This method instructs and assists in the achievement of regional strategies and actions, being, in this study, associated with the assistance technique with multicriteria for decision making, known as the Process Hierarchical Analysis (AHP) technique developed by Saaty (1977), which complements the effectiveness of the method. Finally, the research investigates the natural susceptibility of environments to erosive processes, using the natural vulnerability to erosion as a product, categorizing the area according to the degree of environmental vulnerability to erosive processes.
\end{abstract}

Keywords: Environmental planning; Natural Vulnerability to Erosion; AHP.

Topic: Sistemas de Gestão Ambiental

Reviewed anonymously in the process of blind peer.
Received: $\mathbf{1 1 / 0 8 / 2 0 2 0}$

Approved: 28/09/2020
Celso José Roberto Soares Júnior (ic Instituto Federal de Rondônia, Brasil http://lattes.cnpq.br/9142251427711422 http://orcid.org/0000-0002-1866-4740 celso.junior@ifro.edu.br
Referencing this:

SOARES JÚNIOR, C. J. R.. Utilização da técnica AHP nos índices de vulnerabilidade natural a erosão na bacia hidrográfica do Igarapé São Francisco como suporte para o ordenamento territorial. Revista Ibero Americana de Ciências Ambientais, v.11, n.5, p.694-704, 2020. DOI: http://doi.org/10.6008/CBPC2179-6858.2020.005.0061 
Utilização da técnica AHP nos índices de vulnerabilidade natural a erosão na bacia hidrográfica do lgarapé São Francisco como suporte para o

\section{INTRODUÇÃO}

Fundamentados nos estudos da Ecodinâmica, a Vulnerabilidade natural a erosão de Crepani et al. (1996; 2001) possui a finalidade de apreciar o grau de resistência ambiental perante os processos naturais de evolução da paisagem e da ação antrópica. Atualmente com a instauração de um modelo hegemônico de desenvolvimento e consumo de representação capitalista, o qual necessita de grande exploração de bens da natureza com a finalidade de acúmulo máximo de capital, gera descontrole na forma de utilização dos elementos da natureza.

Registrando mais de 30 anos de desmatamento na Amazônia legal, o Projeto de Monitoramento do Desmatamento da Amazônia Legal por satélite - PRODES aponta que para a área de monitoramento políticas públicas não solucionam, porém amenizam os problemas da clandestinidade de ocupação das terras da união e contínuos crimes ambientais. Deste modo, o estudo de Vulnerabilidade natural a erosão usada como base para o planejamento ambiental na bacia hidrográfica do igarapé São Francisco diz respeito à carência da área de estudo em conduzir os problemas ambientais, visto que a relação entre a sociedade e o ambiente natural denotam grande grau de complexidade.

Observando sempre as limitações das vulnerabilidades dos ecossistemas, o planejamento é um instrumento para ordenar a ocupação e redirecionar as atividades econômicas, com o propósito de auxiliar estratégias e ações de planos regionais. Este estudo propõe orientar o planejamento ambiental e planos de zoneamento, fundamentado na investigação da suscetibilidade natural dos terrenos frente aos processos erosivos, levando em conta os dados embasados nos levantamentos do Plano Agropecuário e Florestal de Rondônia e os métodos propostos por Crepani et al. (1996; 2001).

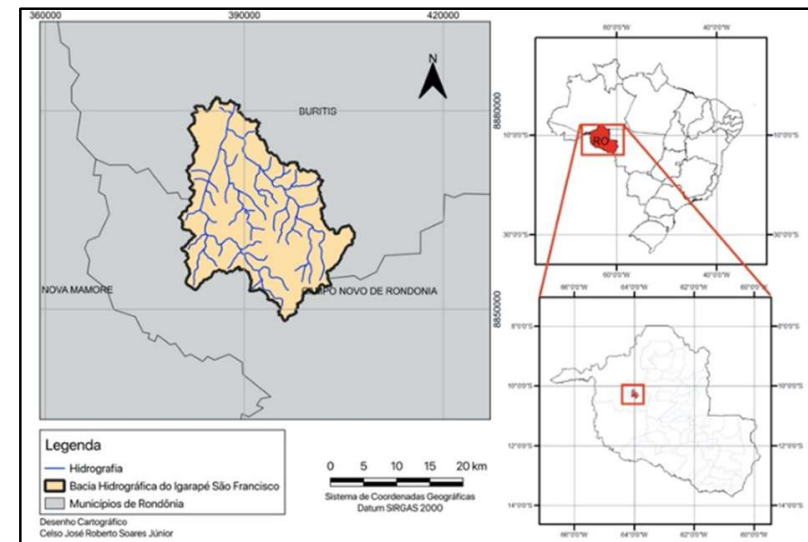

Figura 1: Mapa de localização da Bacia Hidrográfica do Igarapé São Francisco.

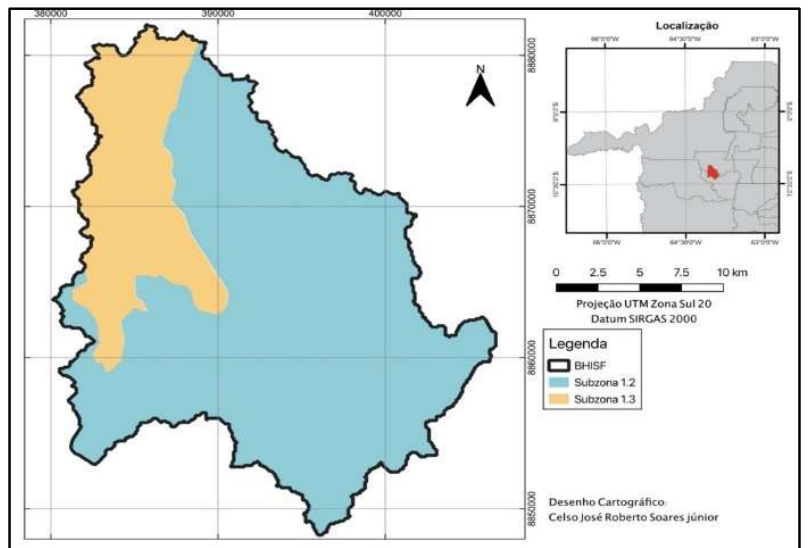

Figura 2: Mapa da bacia hidrográfica do igarapé São Francisco com recorte do ZSEE-RO. Fonte: Base de dados PLANAFLORO, Rondônia (2001).

A bacia hidrográfica do igarapé São Francisco, possui área de 489,87 km² $^{2}$ e encontra-se na porção noroeste do estado do Rondônia (RO) entre os municípios de Campo novo e Buritis, no interior dos paralelos

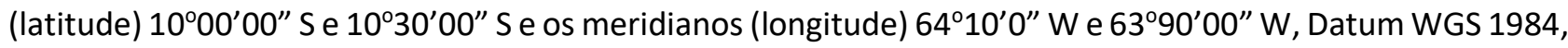
em relação a capital do estado (Porto Velho) possui distância de, aproximadamente, $170 \mathrm{~km}$. De acordo com Ab'Saber (2012), o domínio morfoclimático no qual a bacia em estudo está inserida é o Morfoclimático 
Amazônico, onde apresenta primariamente floresta ombrófila aberta e suas faciações.

Segundo as divisões do estado, por meio do Zoneamento Sócio Ecológico Econômico (ZSEE RO), o qual regulamento determinando tipologias de uso conforme a sua zona, a bacia se encontra em duas subzonas: 1,2 e 1,3. A subzona 1,2 retrata áreas de uso agropecuário e floresta, com evoluído processo de ocupação, por outro lado, a subzona 1,3 busca restringir a sua expansão, privilegiando o aproveitamento dos recursos naturais, conforme é mostrado na figura 2.

\section{REVISÃO TEÓRICA}

\section{Características do meio físico}

\section{Unidades Geomorfológicas}

Com base no PLANAFLORO (RONDÔNIA, 2001), a bacia situa-se sob duas unidades geomorfológicas, consistindo na maioria da sua área em unidades denudacionais de superfícies de aplanamento, com dissecação alta e nenhum ou esporádicos inselbergs e tors (D2231). Este tipo de unidade geomorfológica abrange a maior parcela do território do estado de Rondônia, as superfícies de aplanamento compreendem em extensas superfícies aplanadas, consequência do processo de pediplanação. Em pontos espalhados na bacia localizam-se agrupamentos de morros e colinas, abertos com colinas/inselbergs baixos e médios (D31), apresentando relevos em configurações de morros e colinas, dissecados pela atividade fluvial. Localmente, recebem o nome de serras, devido desníveis de até 150 metros. Uma vez serem abertos com colinas/inselbergs baixos e médios, os topos são convexizados, aparecem vertentes côncavas nas baixas vertentes, o intervalo de altitude é de 480 a 290 metros, nos entalhes de vales possui variação entre 20 a 80 metros, dimensão fluvial dentro dos valores de 250 a 1750 metros e as declividades oscilam de 4 a 15\%.

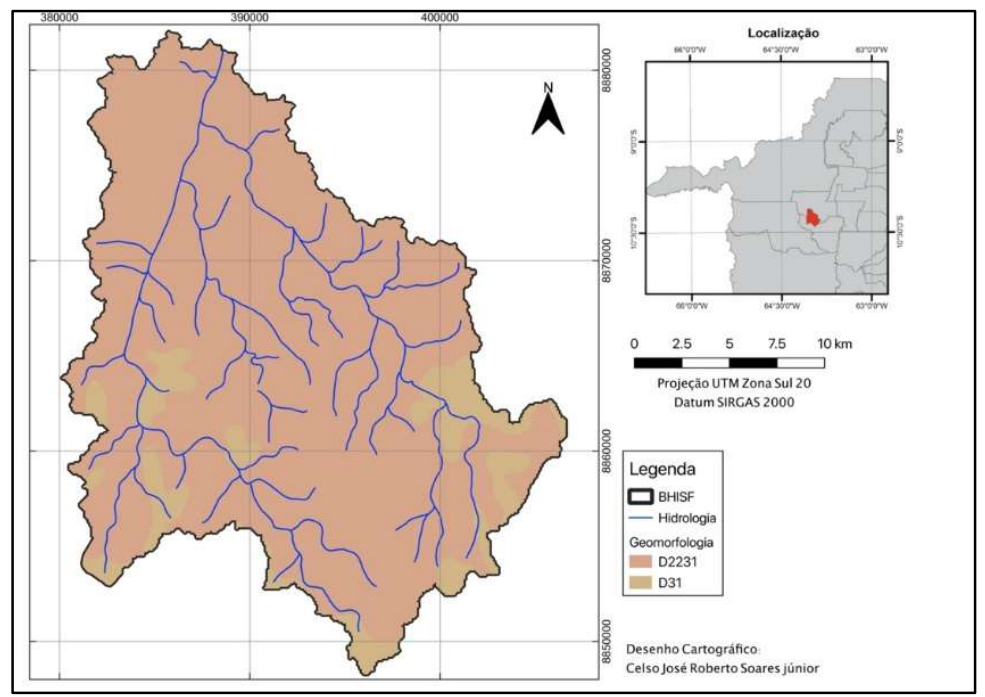

Figura 3: Mapa temático geomorfológico da bacia hidrográfica do igarapé São Francisco. Fonte: Base de dados PLANAFLORO, Rondônia (2001).

\section{Cobertura Vegetal}

Na bacia hidrográfica do igarapé São Francisco a vegetação nativa era a floresta ombrófila com suas 
Utilização da técnica AHP nos índices de vulnerabilidade natural a erosão na bacia hidrográfica do lgarapé São Francisco como suporte para o

demais fácies. Todavia, após grande processo de distribuição de projetos de assentamentos ocorreu a modificação da cobertura e uso da terra em quase a sua plenitude. Então com a alteração da cobertura e uso dominou grandes áreas de pastagens, correspondendo a $84,11 \%$ da área da bacia. Na bacia foram encontradas as seguintes tipologias de uso, conforme tabela abaixo.

Tabela 1: Tipologias de Uso e Ocupação na Bacia Hidrográfica do Igarapé São Francisco.

\begin{tabular}{l|l|l|l} 
Nomenclatura de Uso & Tipologia de uso da terra & $\mathbf{k m}^{\mathbf{2}}$ & $\mathbf{\%} \mathbf{d a}$ área da bacia \\
\hline Áreas antrópicas não agrícolas & Áreas Urbanizadas & 0,61 & $0,13 \%$ \\
\hline Área Antrópica Agrícola & Pastagens & 412,04 & $84,11 \%$ \\
\hline Área Antrópica Agrícola & Cultura permanente & 0,26 & $0,05 \%$ \\
\hline Área Antrópica Agrícola & Sistema Agropastoril & 0,04 & $0,01 \%$ \\
\hline Áreas de Vegetação Natural & Floresta & 75,56 & $15,43 \%$ \\
\hline Áreas cobertas pelos corpos hídricos & Corpo d'água continental & 1,37 & $0,28 \%$ \\
\hline Total & & $\mathbf{4 8 9 , 8 7}$ & $\mathbf{1 0 0 \%}$
\end{tabular}

Fonte: Adaptado de IBGE (2013).

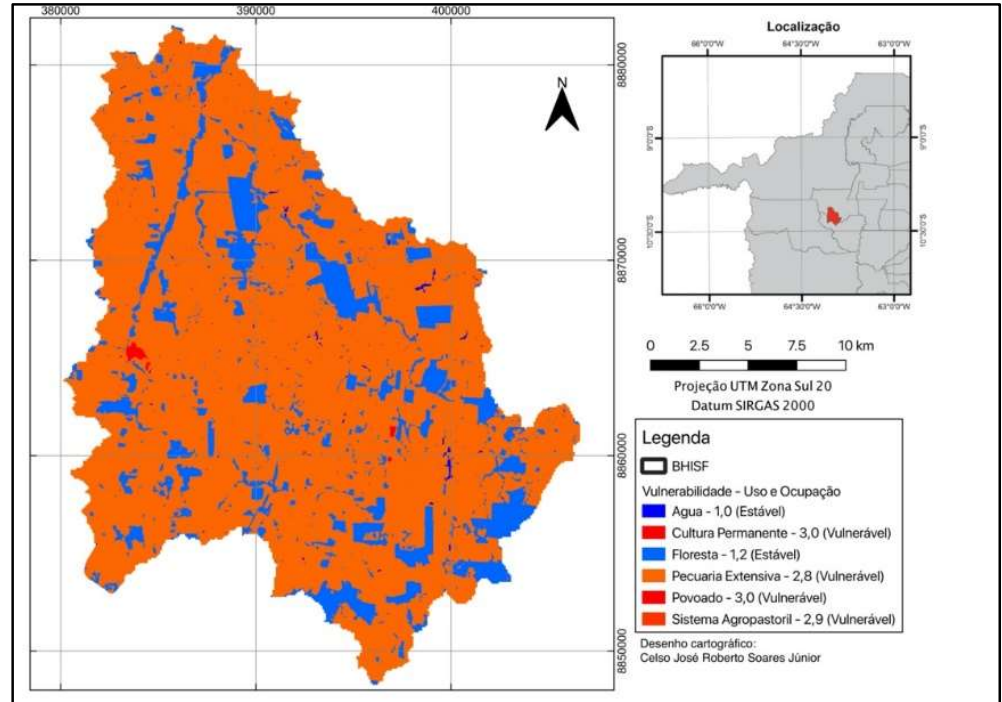

Figura 4: Mapa temático de uso e cobertura da terra. Fonte: Base de dados PLANAFLORO, Rondônia (2001).

\section{Clima}

As características do clima de Rondônia correspondem ao tipo Aw da classificação de Köppen, sendo equatorial de transição tropical, úmido, com forte redução da precipitação no inverno. Ocorrendo período seco nos meses de junho, julho e agosto, obtendo a média anual de três meses secos, passíveis a fortes desvios pluviométricos durante os anos (RODRIGUES, 2015; THÉRY, 2012; SILVA, 2010).

Para a produção da carta de precipitação da área de estudo, foram extraídos dados dos anos de 1980 até 2018, por meio da estação pluviométrica de código 1063000 posicionada no município de Ariquemes, na escola Caramuru, com distância de 56,4 km até a bacia. Conforme, os dados coletados da AGÊNCIA NACIONAL DE ÁGUAS - ANA (2018), os meses mais chuvosos dos anos de 1980 a 2018 foram de novembro a abril, com precipitações médias superiores a $200 \mathrm{~mm} / \mathrm{mês}$, por outro lado, os meses de junho, julho e agosto mostraram médias inferiores a $40 \mathrm{~mm} / \mathrm{mês}$.

\section{Solos}

Na região de estudo foi encontrado majoritariamente representando, aproximadamente, 56\%, o 
Latossolo Vermelho-Amarelo distrófico com Neossolo Litólico Eutrófico (LLD21), de extremo norte a sul da bacia. No noroeste da bacia encontra-se o Latossolo Vermelho-Amarelo Distrófico + Latossolo Amarelo Distrófico (LLD13) com área total de 18\%, com alguns pontos isolados de Latossolo Amarelo Distrófico (LAD8) totalizando $4 \%$ de área da bacia. Em áreas aleatórias dentro da bacia apresentaram argissolo Vermelho Amarelo Distrófico + Latossolo Amarelo Distrófico (PD8) com 16\% da área, Argissolo Vermelho - Amarelo Distrófico (PD3) e Argissolo Vermelho-Amarelo Eutrófico + Latossolo Vermelho - Escuro Eutrófico (PE5), cada um, respectivamente, com $2 \%$ e $4 \%$.

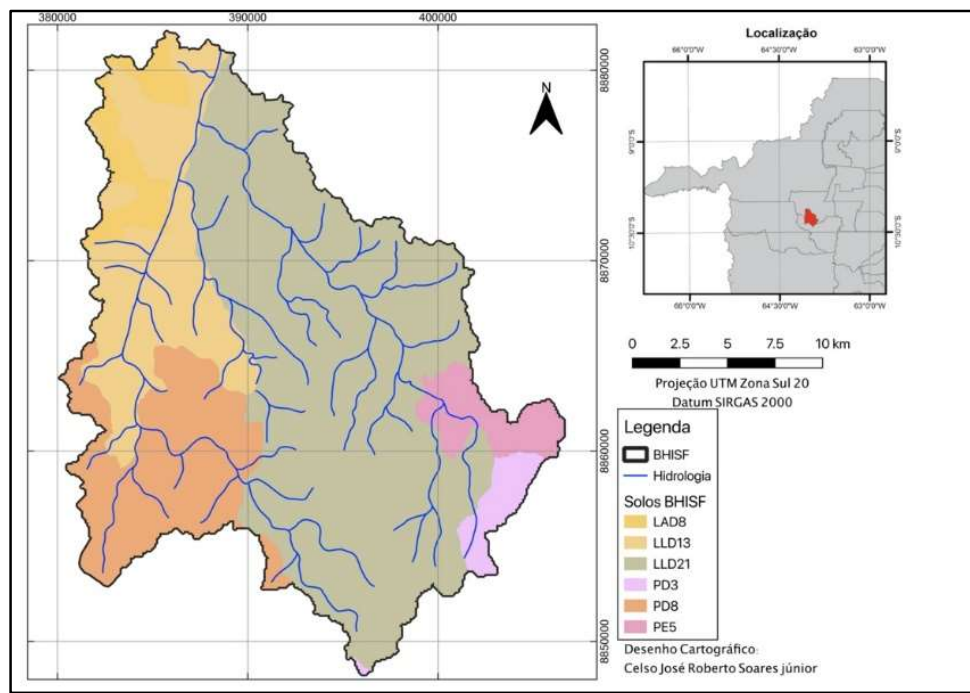

Figura 5: Mapa temático dos grupos de solos da bacia hidrográfica do igarapé São Francisco. Fonte: Base de dados PLANAFLORO, Rondônia (2001).

\section{Geologia}

A Bacia hidrográfica do igarapé São Francisco é representado, conforme PLANAFLORO (RONDÔNIA, 2001), pelo Supergrupo Gnaisse Jaru (PMPja), sendo uma rocha metamórfica, a suíte intrusiva do Teotônio (MPteg), compreendendo de rocha ígnea e Granitos Jovens de Rondônia (Npyg), também ígnea.

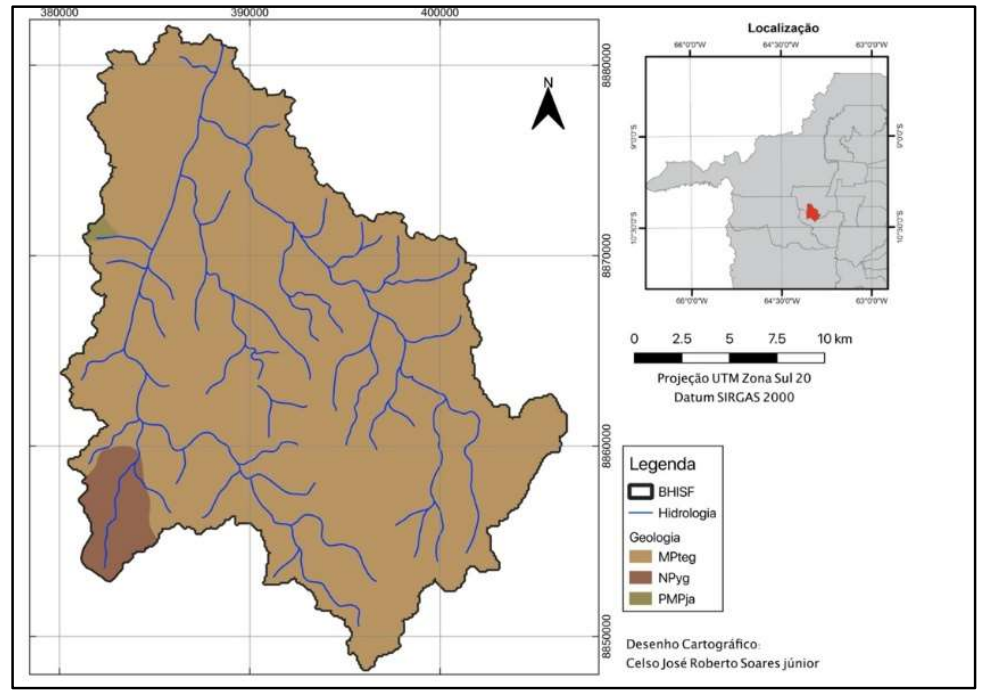

Figura 6: Mapa temático geológico da bacia hidrográfica do igarapé São Francisco. Fonte: Base de PLANAFLORO, Rondônia (2001). 
Utilização da técnica AHP nos índices de vulnerabilidade natural a erosão na bacia hidrográfica do lgarapé São Francisco como suporte para o

\section{METODOLOGIA}

A proposta metodológica de Crepani et al. $(1996 ; 2001)$ foi empregada para realizar a análise da vulnerabilidade natural a erosão dos terrenos. No qual apresenta a apreciação das áreas de acordo com a análise integrada dos elementos do meio físico, resultando em registros cartográficos que apontam a vulnerabilidade dos terrenos aos processos erosivos.

Primeiramente foram realizados levantamentos cartográficos e bibliográficos, com a complementação dos dados de trabalho de campo, e por fim a edição para a produção de mapas temáticos básicos (geologia, solos, geomorfologia, clima e cobertura e uso da terra). O agrupamento dos dados relacionados ao meio físico foi efetuado de forma automatizada, com o uso da ferramenta QGIS 3.8, gerando um produto capaz de identificar a vulnerabilidade natural a erosão daquela área.

\section{Vulnerabilidade Natural a Erosão}

A produção da carta de vulnerabilidade natural do solo a erosão neste estudo utilizará a metodologia de Crepani et al. (1996; 2001), a qual foi utilizada para elaboração do Zoneamento Ecológico e Econômico para a Amazônia, embasada nos conceitos da Ecodinâmica de Tricart (1977). Crepani et al. (1996; 2001) faz a delimitação e identificação das áreas em Unidades Territoriais Básicas (UTBs), divididas em duas categorias: unidades de paisagem natural e os polígonos de intervenção antrópica. A delimitação das unidades é realizada conforme imagem de satélite, segundo interpretação na imagem de padrões iguais, designados pela alternância de cores, formas, texturas relevo e padrões de drenagem (CREPANi et al., 2001).

De acordo com Fagundes (2013), com o objetivo de determinar o nível de vulnerabilidade natural à perda de solo, as Unidades Territoriais Básicas são avaliadas individualmente conforme as informações temáticas previamente inseridas, o qual empregará um modelo capaz de avaliar as suas modificações contínuas no ambiente, avaliando os seus estágios da evolução morfodinâmica. Cada categoria morfodinâmica será outorgado um valor de estabilidade, de forma a produzir uma escala de vulnerabilidade.

Para a elaboração das escalas de vulnerabilidade, Crepani et al. (1996; 2001) confere categorias morfodinâmicas desenvolvidas com base nos princípios da ecodinâmica de Tricart (1977), em que cada categoria recebe valores de estabilidade variando de 1,0 a 3,0 dada a relação Pedogênese/Morfogênese. A medida que os valores se aproximam de 1,0 é garantido a estabilidade no ambiente, por outro lado a medida que o valor se aproxima de 3,0 é conferido ao ambiente a instabilidade. Posterior o reconhecimento dos valores individuais das categorias morfodinâmicas é realizado a soma e obtido a média, procedendo o índice final, que retrata o grau de vulnerabilidade daquela área.

\section{Técnica AHP - Análise Hierárquica Processual}

Com a finalidade de dar base de apoio para tomadas de decisões, a metodologia desenvolvida por Saaty na década de 70 é embasada na matemática possibilitando organiza e avaliar a importância relativa entre os critérios, além de permitir medir a consistência dos seus julgamentos (SPÖRL, 2007). De acordo com 
a dificuldade de se conferir importância e peso nas variáveis, essa proposta auxilia de maneira oportuna o processo de tomada de decisões, conforme a relevância de cada critério utilizado no processo analisado, descreve Rodrigues (2015).

Conforme Sena (2008), nessa técnica, a decisão a ser tomada é baseada em critérios qualitativos e quantitativos, analisada por pontos de vistas diferenciados e divergentes. A técnica demonstra como um de seus princípios a separação dos problemas complexos em problemas mais simples, arquitetados através de hierarquia de decisão.

Com isso, a técnica AHP precisa de uma elaboração de uma hierarquia de decisão, composta por níveis ou classes hierárquicas, possibilitando ter uma visão geral das relações inerentes ao processo. A definição da importância relativa para cada fator de hierarquia é realizada através de matrizes de comparação para cada nível, no qual os resultados das matrizes são ponderados entre si (SILVA et al., 2009)

Os diferentes fatores que influenciam a tomada de decisão são ordenados em um padrão hierárquico em escala de importância, variando de um (1) a nove (9), em que o valor um (1) revela o mínimo, enquanto o nove (9) é relacionado ao máximo de importância. Posterior à determinação do valor para cada fator é realizada a comparação pareada (pairwise comparison), concedendo um valor de importância relativo (peso), ordenados em uma matriz de comparação ou pareadas (SILVA et al., 2009).

Tabela 2: Escalas de comparação, conforme Saaty (1977).

\begin{tabular}{l|l} 
Importância & Valores \\
\hline Igual importância & 1 \\
\hline Importância pequena de uma sobre a outra & 3 \\
\hline Importância grande ou essencial & 5 \\
\hline Importância muito grande ou demonstrada & 7 \\
\hline Importância absoluta & 9 \\
\hline Valores intermediários & $2,4,6$ e 8. \\
\hline
\end{tabular}

Fonte: Adaptado de Saaty (1977).

\section{RESULTADOS E DISCUSSÃO}

\section{Técnica AHP dos temas da Vulnerabilidade Natural a Erosão}

Baseado na importância relativa discutido acima, houve a hierarquização dos fatores que envolvem a vulnerabilidade natural a erosão. Em ordem crescente de importância temos: grau de importância 1: Geologia; grau de importância 3: Clima; grau de importância 5: Solos; grau de importância 7: Vegetação/Uso; e grau de importância 9: Geomorfologia. Após o estabelecimento das comparações par a par na técnica de Análise Hierárquica Processual, obteve-se os seguintes pesos para os determinados temas:

Tabela 3: Pesos calculados para VNE na Bacia Hidrográfica do igarapé São Francisco.

\begin{tabular}{l|l} 
Temas & Pesos \\
\hline Geologia & 0,0345 \\
\hline Clima & 0,0674 \\
\hline Solo & 0,1342 \\
\hline Vegetação/Uso & 0,2599 \\
\hline Geomorfologia & 0,5028 \\
\hline
\end{tabular}

Dessa maneira, os valores atribuídos para cada fator componente do sistema são aplicados na 
seguinte equação (1) para a elaboração da carta de vulnerabilidade natural a erosão. Onde: Va, o mapa de vulnerabilidade antrópico; P1, P2, P3, P4, P5, são os pesos estatísticos calculados para cada elemento; V, é a atribuição dos graus de vulnerabilidade, conforme Crepani et al. (2001).

$$
\begin{aligned}
& \text { Va }=(P 1 \times \text { Vgeol })+(P 2 \times \text { Vclima })+(P 3 \times \text { VSolo })+(P 4 \times \text { Vveg } / \text { uso }) \\
& +(P 5 \times \text { Vgeom })
\end{aligned}
$$

\section{Vulnerabilidade Natural a Erosão}

O mapa de vulnerabilidade natural a Erosão, sem a utilização da técnica AHP, apresentou dois graus de escala de vulnerabilidade: 34,12\% moderadamente estável e 65,88\% medianamente estável/vulnerável, conforme mostra a figura 7.

\begin{tabular}{|c|c|c|c|}
\hline Graus de Vulnerabilidade & Área $\left(\mathrm{km}^{2}\right)$ & \% da área & Agrup. dos graus de vulnerabilidade \\
\hline 1,4 (Moderadamente estável) & 12,57 & $2,57 \%$ & \multirow{4}{*}{$34,12 \%$} \\
\hline 1,5 (Moderadamente estável) & 43,40 & $8,86 \%$ & \\
\hline 1,6 (Moderadamente estável) & 18,07 & $3,69 \%$ & \\
\hline 1,7 (Moderadamente estável) & 93,08 & $19,00 \%$ & \\
\hline 1,8 (Medianamente estável/vulnerável) & 229,81 & $46,91 \%$ & \multirow{2}{*}{$65,88 \%$} \\
\hline 1,9 (Medianamente estável/vulnerável) & 92,94 & $18,97 \%$ & \\
\hline Total & 489,87 & $100,00 \%$ & $100,00 \%$ \\
\hline
\end{tabular}

Tabela 4: Área dos graus de Vulnerabilidade da Bacia, sem AHP.

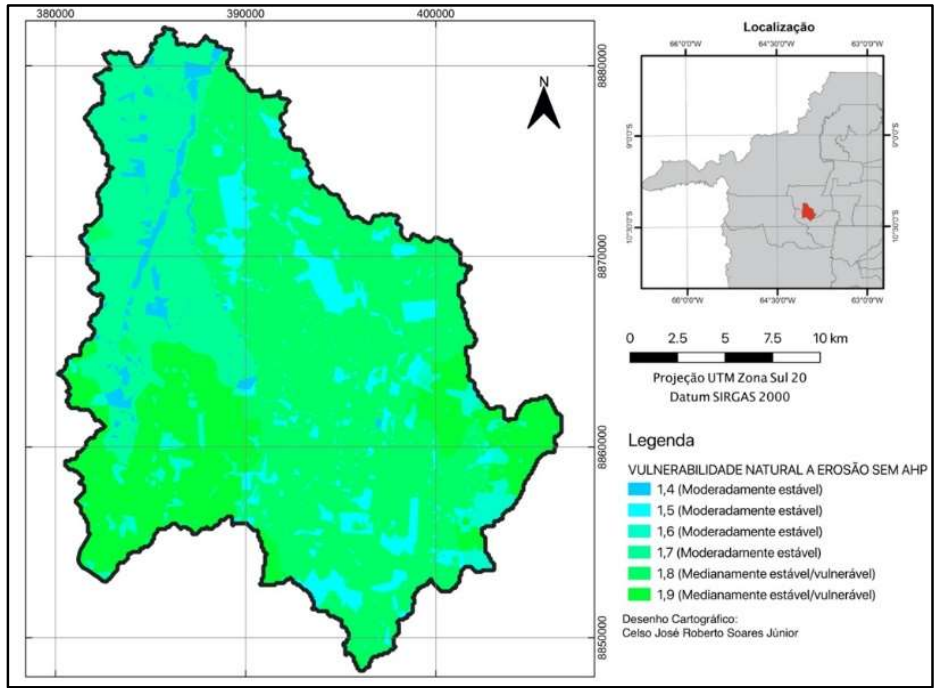

Figura 7: Mapa de Vulnerabilidade Natural a Erosão da Bacia sem AHP. Fonte: Base de dados PLANAFLORO, Rondônia (2001).

O expressivo valor intermediário de vulnerabilidade da área é consequência do progressivo processo de abertura e ocupação de novas terras, no qual a pecuária é a atividade produtiva predominante. Com essa alteração há uma mudança nas faixas de vegetação, tornando uma floresta estratificada em uma formação vegetacional com alturas máximas de 2 metros, com estrato mais herbáceo-arbustiva.

Quando realizado a equação (1) para obtenção da Vulnerabilidade Natural a Erosão com AHP, observa-se que na distribuição dos pesos houve o maior 'balanceamento' na geomorfologia em relação aos outros temas, com peso de 0,5028, enquanto o menor peso distribuído foi para geologia de 0,0354. Com isso, os valores já medianos acabam por elevando com esse 'balanceamento', apresentando valores maiores 
que o mapa síntese sem Análise Hierárquica Processual (AHP). Desta forma, temos uma redução significante do grau de vulnerabilidade moderadamente estável, representando $15,11 \%$. Por outro lado, o grau de vulnerabilidade medianamente estável/vulnerável saltou para $84,90 \%$ da área da bacia.

Tabela 5: Área dos graus de vulnerabilidade natural a erosão com AHP.

\begin{tabular}{|c|c|c|c|}
\hline Graus de vulnerabilidade & Área $\left(\mathbf{k m}^{2}\right)$ & $\%$ de área & Agrupamento de graus de vulnerabilidade \\
\hline 1,5 (Moderadamente estável) & 13,51 & $2,76 \%$ & \multirow{3}{*}{$15,11 \%$} \\
\hline 1,6 (Moderadamente estável) & 50,04 & $10,21 \%$ & \\
\hline 1,7 (Moderadamente estável) & 10,49 & $2,14 \%$ & \\
\hline 1,9 (Medianamente estável/vulnerável) & 92,64 & $18,91 \%$ & \multirow{3}{*}{$84,89 \%$} \\
\hline 2,0 (Medianamente estável/vulnerável) & 281,56 & $57,48 \%$ & \\
\hline 2,2 (Medianamente estável/vulnerável) & 41,63 & $8,50 \%$ & \\
\hline Total & 489,87 & $100,00 \%$ & $100,00 \%$ \\
\hline
\end{tabular}

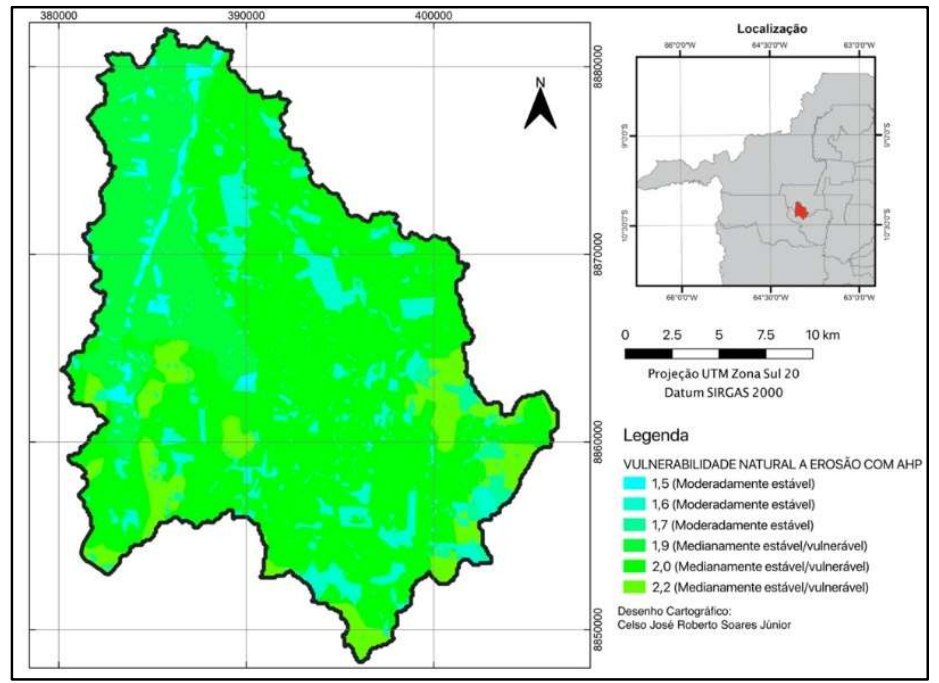

Figura 8: Mapa de vulnerabilidade natural a erosão com AHP. Fonte: Base de dados PLANAFLORO, Rondônia (2001).

Na metodologia de Vulnerabilidade Natural a Erosão sem o uso da AHP, apresenta uma grande área moderadamente estável, isto devido aquela localidade possuir uma grande influência do solo latossolo vermelho-amarelo distrófico, representando na escala de vulnerabilidade valor de 1,0 (estável), quando colocada na equação de Crepani et al. (2001) acarreta em diminuição das escalas dos outros temas.

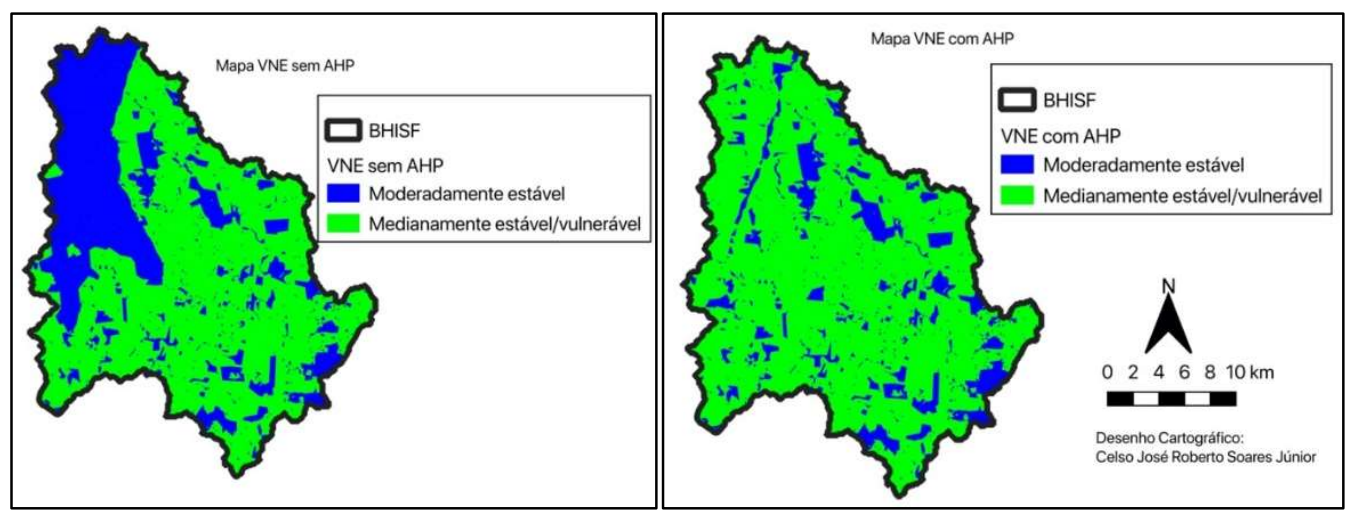

Figura 9: Comparação entre os mapas de vulnerabilidade natural a erosão com e sem AHP. Fonte: Base de dados PLANAFLORO, Rondônia (2001). 
Utilização da técnica AHP nos índices de vulnerabilidade natural a erosão na bacia hidrográfica do lgarapé São Francisco como suporte para o

Tabela 6: Comparação dos mapas de vulnerabilidade natural a erosão com e sem AHP.

\begin{tabular}{l|l|l} 
Metodologia & Moderadamente estável $\left.\mathbf{( k m}^{\mathbf{2}}\right)$ & Medianamente estável/Vulnerável (km²) \\
\hline Vulnerabilidade natural a Erosão sem AHP & 167,14 & 322,75 \\
\hline Vulnerabilidade Natural a erosão com AHP & 74,04 & 415,83 \\
\hline
\end{tabular}

Com a realização da técnica AHP houve a atribuição dos pesos de maior importância para menor importância na seguinte ordem geomorfologia, vegetação/uso, solo, clima e geologia. Pode-se observar que o tema vegetação/uso é a segunda mais importante, com a majoração houve um destaque da área de floresta no uso e cobertura da terra quando realizado o cálculo de vulnerabilidade natural a erosão com AHP, resultando nas duas análises as mesmas áreas de vulnerabilidade estável. Desta forma, há muita similaridade entre os mapas de vulnerabilidade natural a erosão com AHP e o mapa temático de uso e cobertura da terra, como pode observar na imagem abaixo.
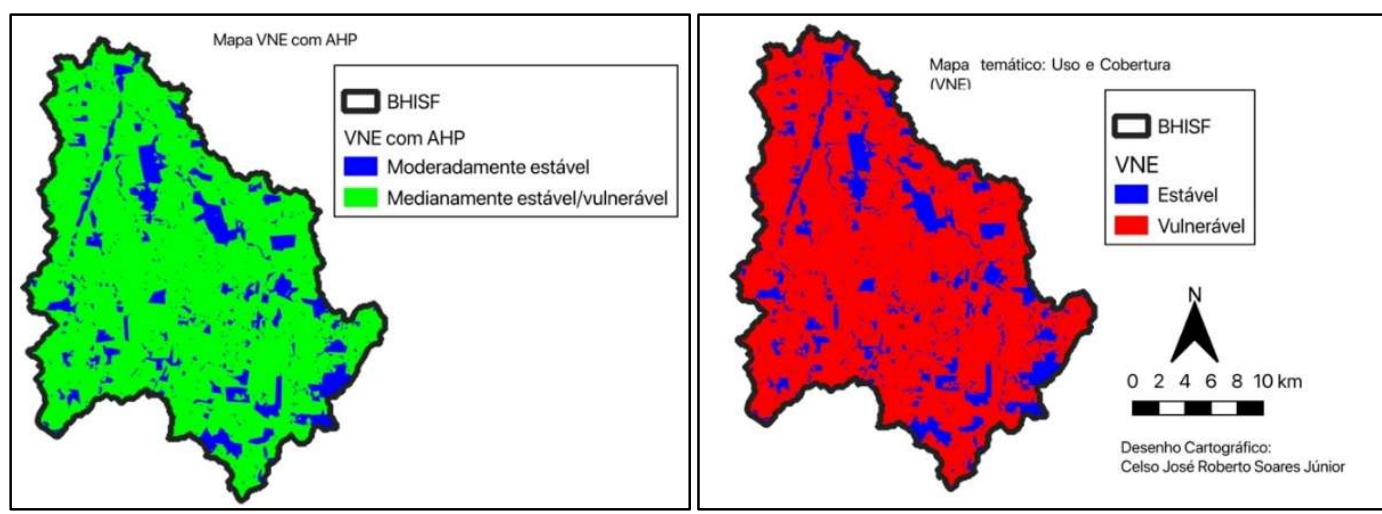

Figura 10: Comparação mapa de vulnerabilidade natural a erosão com AHP com mapa temático de uso e cobertura da terra. Fonte: Base de dados PLANAFLORO, Rondônia (2001).

\section{CONCLUSÕES}

As áreas em que mostraram menos vulneráveis a erosões foram situadas em zonas com cobertura vegetal preservadas, havendo assim a prevalência dos processos pedogenéticos em relação aos processos morfogenéticos. Ainda que a área de estudo possui uma quantidade expressiva de áreas de uso antrópico, aproximadamente $84 \%$, as análises realizadas, tanto com quanto sem o uso da Técnica AHP, aponta que a bacia está com o equilíbrio entre morfogênese e pedogênese.

Segundo o Zoneamento Sócio Ecológico Econômico de Rondônia, 78\% da área da bacia se encontra na subzona 1.2 , e $22 \%$ na subzona 1.3. Constatando que a subzona 1.3 deveria priorizar o aproveitamento dos recursos naturais daquela área não promovendo a expansão agropecuária, de acordo com a lei complementar, os levantamentos apresentaram que desde o início da década de 2000, houve um aumento progressivo da exploração de terras, por meio da produção pecuária, deste modo a área exige a atenção do poder público visto o aparecimento de novas propriedades rurais naquela subzona.

A utilização do estudo de vulnerabilidade natural a erosão com o intuito de assimilar a dinâmica dos fenômenos que atual e que determinam a evolução de um determinado terreno, assim como também as formas de ajustamentos daquele lugar, são bastante eficientes. Todavia, é necessário requerer que as análises integrem dados mais detalhados, tanto espacialmente quanto temporalmente, para que esse estudo proporcione parâmetros mais seguros. 
A categorização da área conforme o grau de vulnerabilidade com relação aos processos erosivos, revela-se como um dispositivo pertinente para orientação de planos de zoneamento e planejamento ambiental da bacia estudada, a qual está situada em uma zona de grande relevância ambiental na área noroeste do estado de Rondônia.

\section{REFERÊNCIAS}

AB'SABER, A.. Os domínios de natureza no Brasil: Potencialidades Paisagísticas. 7 ed. São Paulo: Ateliê, 2012.

ANA. Agência Nacional de Águas. Portal Hidro Web: Séries Históricas de Estações. ANA, 2018.

CREPANI, E.; MEDEIROS, J. S.; AZEVEDO, L. G.; HERNANDEZ FILHO, P.; FLORENZANO, T. G.; DUARTE, V.. Curso de sensoriamento remoto aplicado ao zoneamento ecológicoeconômico. São José dos Campos: Instituto Nacional de Pesquisas Espaciais, 1996.

CREPANI, E.; MEDEIROS, J. S.; AZEVEDO, L. G.; HERNANDEZ FILHO, P.; FLORENZANO, T. G.; DUARTE, V.; BARBOSA, C. C. F.. Sensoriamento remoto e geoprocessamento aplicados ao zoneamento ecológico-econômico e ao ordenamento territorial. São José dos Campos: Instituto Nacional de Pesquisas Espaciais, 2001.

FAGUNDES, M. G.. Estudo comparativo da variação de escala na fragilidade ambiental e vulnerabilidade natural do solo na Bacia Hidrográfica do Rio Jundiaí. Dissertação (Mestrado em Geografia Física) - Universidade de São Paulo, São Paulo, 2013.

IBGE. Instituto Brasileiro de Geografia e Estatística. Manual técnico de uso da terra. 3 ed. Rio de Janeiro: IBGE, 2013.

RODRIGUES, T. B.. Caracterização e análise do uso e cobertura da terra na bacia hidrográfica do Igarapé do Contra, Porto Velho/RO: Implicações a partir da Vulnerabilidade à erosão. Dissertação (Mestrado em Geografia) - Universidade Federal de Rondônia, Porto Velho, 2015.
RONDÔNIA. PLANAFLORO - Plano Agropecuário e Florestal de Rondônia: Relatório Técnico. Porto Velho, 2001.

SAATY, T. L.. A scaling method for priorities in hierarchical structures. Journal of Mathematical Psychology, v.15, n.3, p.234-281, 1977. DOI: https://doi.org/10.1016/00222496(77)90033-5

SENA, J. N.. O uso de sistema de informação geográfica na avaliação de diferentes alternativas de geração de cartas de suscetibilidade à erosão. Dissertação (Mestrado em Engenharia Civil) - Universidade Estadual Paulista, Ilha Solteira, 2008.

SILVA, C. A.; NUNES, F. P.. Mapeamento de vulnerabilidade ambiental utilizando o método AHP: uma análise integrada para suporte à decisão no município de Pacoti/CE. In: SIMPÓSIO BRASILEIRO DE SENSORIAMENTO REMOTO, 14. Anais. Natal: INPE, 2009.

SILVA, M. J. G.. Uso e Cobertura do Solo e a Variabilidade do Clima de Porto Velho/RO. Dissertação (Mestrado em Desenvolvimento Regional) - Universidade Federal de Rondônia, Porto Velho, 2010.

SPÖRL, C.. Metodologia para elaboração de modelos de fragilidade ambiental utilizando redes neurais. Tese (Doutorado em Geografia Física) - Universidade de São Paulo, São Paulo, 2007.

THÉRY, H.. Rondônia mutações de um Território federal na Amazônia federal. Curitiba: SK, 2012.

TRICART, J.. Ecodinâmica. Rio de Janeiro: IBGE, 1977.

A CBPC - Companhia Brasileira de Produção Científica (CNPJ: 11.221.422/0001-03) detém os direitos materiais desta publicação. Os direitos referem-se à publicação do trabalho em qualquer parte do mundo, incluindo os direitos às renovações, expansões e disseminações da contribuição, bem como outros direitos subsidiários. Todos os trabalhos publicados eletronicamente poderão posteriormente ser publicados em coletâneas impressas sob coordenação da Sustenere Publishing, da Companhia Brasileira de Produção Científica e seus parceiros autorizados. Os (as) autores (as) preservam os direitos autorais, mas não têm permissão para a publicação da contribuição em outro meio, impresso ou digital, em português ou em tradução. 